\title{
Neither mindful nor mindless, but minded: habits, ecological psychology, and skilled performance
}

\author{
Miguel Segundo-Ortin ${ }^{1} \cdot$ Manuel Heras-Escribano $^{2}(\mathbb{D}$
}

Received: 4 June 2020 / Accepted: 28 May 2021 / Published online: 30 June 2021

(c) The Author(s) 2021

\begin{abstract}
A widely shared assumption in the literature about skilled motor behavior is that any action that is not blindly automatic and mechanical must be the product of computational processes upon mental representations. To counter this assumption, in this paper we offer a radical embodied (non-representational) account of skilled action that combines ecological psychology and the Deweyan theory of habits. According to our proposal, skilful performance can be understood as composed of sequences of mutually coherent, task-specific perceptual-motor habits. Such habits play a crucial role in simplifying both our exploration of the perceptual environment and our decision-making. However, we argue that what keeps habits situated, precluding them from becoming rote and automatic, are not mental representations but the agent's conscious attention to the affordances of the environment. It is because the agent is not acting on autopilot but constantly searching for new information for affordances that she can control her behavior, adapting previously learned habits to the current circumstances. We defend that our account provides the resources needed to understand how skilled action can be intelligent (flexible, adaptive, context-sensitive) without having any representational cognitive processes built into them.
\end{abstract}

Keywords Skilled action · Affordances · Information $\cdot$ Habits $\cdot$ Radical embodied cognition $\cdot$ Direct perception $\cdot$ Ecological psychology

This article belongs to the topical collection "Minds in Skilled Performance", edited by Katsunori Miyahara, Ian Robertson and Michael Kirchhoff.

Miguel Segundo-Ortin

miguel.segundo.ortin@gmail.com

Manuel Heras-Escribano

herasescribano@gmail.com

1 Department of Philosophy and Religious Studies, Faculty of Humanities, Utrecht University, Utrecht, The Netherlands

2 Department of Philosophy I, University of Granada, Granada, Spain 


\section{Introduction}

A mark of intelligent, skilled action is adaptive flexibility. In order to achieve their goals, expert agents-e.g., athletes-must be able to control their actions, responding in an appropriate manner to the demands and contingencies of the situation. For those interested in performance studies, the problem is to explain how such adaptive flexibility is possible. One possible explanation is offered by defenders of intellectualism (see Stanley \& Krakauer, 2013). According to intellectualists, skillful control requires engaging in propositional thinking. It follows from this view that the intelligence of skilled actions derives from the fact that they are guided by conscious propositions and explicit reasoning. Yet, as Sutton et al. (2011) note, as soon as we reflect upon the fast-changing dynamics of the circumstances where athletes perform, we find the idea that skilled action involves the application of explicit, propositionally articulated deliberation hard to believe.

On the opposite side of the spectrum, we find those who defend what Montero (2013) calls the "automaticity principle." According to this view, skilled action consists of the unconscious deployment of automated motor routines. The skilled actor, supporters of this view contend, has reached a level of expertise that allows her to react to the impingements of the performing situation without being aware of her actions and the details of the situation itself. ${ }^{1}$

Nonetheless, even if we can agree that there is probably no time for conscious planning and deliberation in situations that require rapid and coordinated responses, it is not clear how an action can be mindlessly automatic and intelligent at the same time. In other words, it is not clear how an agent can exert control over her actions, adjusting it in a flexible, context-sensitive way if she is performing with little or no attention to what she is doing.

Motivated by this worry, a series of authors (see Bermúdez, 2017; Christensen et al., 2016; Fridland, 2014, 2017a; Pacherie \& Mylopoulos, 2020) have tried to articulate accounts of skilled motor behavior that avoid both over-intellectualizing and under-intellectualizing it. According to these middle-ground views, skilled actions are neither mindful (based on conscious reflection) nor mindless (purely reactive and automatic), but minded, meaning that the skilled performer has some form of cognitive control over them. However, because these authors assume that any action that is not blindly automatic or mechanical must be the result of some representational cognitive process, their proposed explanation for skilled performance takes for granted that such control over action depends on the existence of top-down representational processes.

\footnotetext{
${ }^{1}$ It is easy to find testimonies by athletes who suggest that the automaticity principle, or something near enough, is true. Consider the words of cricket Ken Barrington: “when you're playing well you don't think about anything and run-making comes naturally" (quoted in Sutton, 2007, p. 767). Or basketball legend Larry Bird: "[A lot of the] things I do on the court are just reactions to situations. [...] A lot of the times, I've passed the basketball and not realized I've passed it until a moment or so later'(quoted in Breivik, 2007, p. 129). According to Høffding and Montero (2020), these examples can be explained by appealing to "expert-induced amnesia.".
} 
This paper reacts against this third way and its main assumption. Instead, we sketch an outline for a radical embodied, non-representational theory of skilled motor behavior based on the combination of ecological psychology (Gibson, 1979[2015]; Chemero, 2009) and the philosophy of Dewey. In order to justify this connection, it is worth mentioning that Dewey anticipated many important ideas also present ecological psychology (see Heras-Escribano, 2019b; Crippen, 2017, 2020; Crippen \& Schulkin, 2020). First, he rejected the assumption that perception is a passive happening whereby the agent is impressed by some external stimuli. Instead, he conceived of it as "an act of the going-out [...] in order to receive" (Dewey, 1934[2005], p. 55). He also introduced the idea that perception is embodied by claiming that the sensory systems operate in connection with the rest of the body in exploring and manipulating the environment (p. 104). Finally, in his now classical piece on the reflex arc (1896), Dewey rejected that perception and action can be separated as discrete input and output units.

In this paper, we will elaborate on Dewey's theory of habit (1922[2007]). We hold that Dewey's theory of habit can be considered a natural ally for an ecological approach to skilled action. For instance, his claim that habits are ways of incorporating the environment (1922[2007], p. 15) fits well both with the ecological claim that the minimum unit of analysis is the animal-environment system, and with the more recent claim that skill learning extends to the environment (Baggs et al., 2020).

Our argument is two-fold. First, we argue that the empirical evidence gathered by ecological psychologists shows that intelligent, skilled action is possible on the basis of direct perception, and that complex behavioral solutions that seem to require mental representations can be simplified by capitalizing on affordance-specific perceptual information. Second, we argue that the Deweyan theory of habits shows how skillful performance can be structured as different kinds of dispositions and sets of exploratory repertoires that are deployed to satisfy the agent's needs, being these dispositions executed and tailored to the circumstances thanks to direct perception. Such habits, we argue, play a crucial role in simplifying both our exploration of the perceptual environment and our decision-making. Importantly, while we do not deny that cognitive representations might enter the picture in some cases (namely, in the form of episodic memories, self-directed speech, etc.), we reject that the kind of cognitive control commonly associated with skilled action must always involve representational processes. In short, we propose an account of skilled action that does not start by assuming a representational explanatory framework for cognition.

The structure of this paper is as follows. In Sect. 1, we critically survey the automaticity principle. In Sect. 2, we turn to representational theories of skilled action. We argue, however, that the arguments for representationalism in skilled motor behavior are based on an unjustified assumption according to which if an action is not blindly automatic, it must be caused by some representational cognitive process. The remaining of the paper counters this assumption by elaborating on a nonrepresentational approach to skilled motor behavior. Section 3 begins this approach by explaining the ecological approach to perception and action and shows how it applies to debates about skilful performance. To finish up, Sect. 4 articulates the combination of ecological psychology and the Deweyan notion of habit. 


\section{The automaticity principle}

As Barbara Montero (2016) claims, there is an influential assumption in the literature of skilled action according to which "an expert is an individual who has developed her skills to the point where they have become effortless and automatic" (p. 54).

Papineau $(2013,2015)$ exemplifies this view when he characterizes motor behavior as automatic and reflex-like. He reaches this conclusion after analyzing the dynamics involved in cricket batting. As he tells us, top-rank bowlers project the ball at a batsman from about $18 \mathrm{~m}$ distant at speed in range $80-160 \mathrm{~km} / \mathrm{h}$. This means that the interval since the moment the ball is released to the moment it reaches the batsman ranges 0.8 to $0.4 \mathrm{~s}$. According to Papineau, the kind of actions involved in batting are too fast for conscious decision-making to intercede between the visual detection of the ball's trajectory and the stroke. In his own words: "there is no room for real-time conscious decision in bating. Batting is automatic, not under conscious control. There is no time to think once the ball has been released. You can only react" (2013, p. 177).

Papineau generalizes this claim to all skilled actions:

Skilled sporting movements need to be automatic. A competitor who starts thinking consciously about the movement they are about to perform will find themselves reduced to the level of the novice who has not yet acquired any automatic routines. (pp. 180-181, emphasis original)

Papineau nonetheless makes room for conscious attention and awareness to have an impact on the automatic, reactive actions of skilled agents. At any stage of a game, he argues, a competent batsman will have to stop and assess the situation to form a strategy or plan about how to bat. This plan:

set[s] the parameters of the basic action-control system [...] It will take one raft of conditional dispositions from the batsman's repertoire, and reconfigure that basic control system so that it embodied just those dispositions [...] Having been to reset, the basic action-control system will then respond accordingly, without any further intrusion of conscious thought. (p. 191)

So, on Papineau's account, conscious deliberation plays the role of forming practical intentions that "set the parameters" of the agent's motor-control system. However, once the motor-control system is set, it runs autonomously-this is, without the agent being aware of it (p. 177) —reacting to the environmental impingements in an automatic, reflex-like fashion. Since, according to Papineau, conscious attention requires adopting a reflective, conceptually articulated stance that necessarily impedes action execution, experts must withdraw conscious attention while acting. After the plan has been made, masters must let their reflexes take over.

Another author commonly associated with the automaticity principle is Hubert Dreyfus (see Montero, 2013, 2016; Christensen et al., 2016; Frindland, 2014; Gallagher, 2017; White, 2020). Drawing upon Merleau-Ponty's embodied phenomenology, Dreyfus contends that skill learning involves transitioning from the conscious 
deliberation characteristic of novices to the "intuitive" behavior that is proper of experts. According to him, the expert agent does not need to consider different options about how to act. Rather, "thanks to a vast repertoire of situational discriminations, he sees how to achieve his goal" (2006, p. 47). Besides, the expert has built a rich repertoire of ready-made action patterns, so that "[a]fter responding to hundreds of thousands of specific cases, the expert in a new situation spontaneously does something similar to what has previously worked, and lo and behold, it usually works" (p. 47).

It is nonetheless fair to say that, unlike Papineau, Dreyfus does not explicitly endorse the view that skilled actions are automatic and reflex-like (but see White, 2020 , p. 226). ${ }^{2}$ One reason why Dreyfus is taken to support this view is his somewhat ambiguous position concerning the role that awareness plays in the unfolding of skills. For instance, whereas he is known for defending that skilled coping is marked by a lack of reflective, conceptually articulated awareness that nonetheless allows the expert to make all kinds of subtle discriminations in action (2007b, p. 346), he sometimes implies that peak performance depends on withdrawing all forms of awareness $\left(2013\right.$, p. 31 ; ff. 43, p. 38; 2002, p. 372; 2007a, p. 374). ${ }^{3}$ Secondly, even though he denies that the skilled actors' movements are ballistic, he offers a picture of skilled performance where the expert is passively drawn by the environment into specific courses of action (2007a, p. 374). ${ }^{4}$

Determining whether Dreyfus is rightly regarded as a supporter of the automaticity principle is beyond our current interest in this paper. Instead, we are interested in analyzing the merits of the principle itself. One fundamental problem with this view is that it is not clear how skilled actions can be reflex-like and intelligent at the same time. Because athletes are continuously subjected to a high degree of unpredictability, they must be prepared to make immediate, spontaneous adjustments to their previously initiated action sequences in light of these new environmental contingencies. In fact, it is reasonable to think that it is the capacity to continuously modify, adjust, and revise the cu2017rrent performance in light of emerging task goals and unexpected contingencies what constitutes the mark of intelligent action, and what most notably sets experts and novices apart. This flexibility requires that the agent maintains some cognitive control over her actions. We agree with other authors (Fridland, 2014; Levy, ; Pacherie \& Mylopoulos, 2020) that this condition poses a problem for the automaticity principle: If skilled actions are automatically triggered by particular environmental cues and unfold without the agent's awareness then they cannot be controlled. It follows from this that an agent who acts in a purely automatic way "would come close to the zero-intelligent agent" (Gallagher \& Varga,

\footnotetext{
2 We thank an anonymous reviewer for the pointer.

3 See, e.g., Gallagher \& Varga (2020, p. 3) and White (2020, p. 219) for other Dreyfus scholars that have reached the same conclusion.

${ }^{4}$ For Dreyfus, skilled action "while passive, is not a mere compulsion [for] I can stop doing what I'm doing" (2002, p. 380). According to Fridland (2014), this suggests that the agent's control is restricted to this 'all-or-nothing' intervention, whereas the specific details of the action are left to the environment.
} 
2020, p. 3). Bluntly put, if mastering a skill involves nurturing adaptive flexibility, then agents cannot let their reflexes run on their own.

Note, however, that we do not defend intellectualism here. Even though we believe that experts are often aware of the performing situation in order to act intelligently, we do not claim that this awareness necessarily implies "stepping back" and engaging in abstract conscious deliberation. In our view, cognitive control upon action does not necessarily require conscious propositional thought. Instead, we agree with Sutton and colleagues (2011) that there is a rich, under-explored space between mindful ratiocination and mindless automaticity. Following them, we call this in-between space "minded." What we disagree with Sutton and colleagues is that this in-between approach necessarily requires the adoption of a representational approach to cognition.

\section{On representational theories of expertise}

A series of authors have reacted against both automatic and intellectualist accounts of skilled action and have proposed a somewhat more nuanced view of it. One such author is Fridland (2014b, 2017a). According to Fridland, although skill learning involves some degree of automation, such automation does not imply a total lack of awareness and control. To defend this thesis, she draws on empirical evidence from Optimal Control Theory (Todorov \& Jordan, 2002). According to Optimal Control Theory, as motor skills develop, sensorimotor routines undergo a reduction in movement variability that concerns task-relevant dimensions primarily. This reduction in the degrees of freedom of the task-relevant kinematics is referred to as the Minimum Intervention Principle (MIP). In essence, the MIP highlights that the basic movements that constitute a motor skill do not undergo a uniform, undifferentiated reduction in variability. Rather, this reduction tends to affect more prominently the movements that have a direct impact on the achievement of the task goal. For Fridland, the fact that the motor system can "differentiate" in situ what is relevant for achieving task success shows that the motor system does not simply execute fixed strategies that have been pre-selected for. Rather, it suggests that the motor system, which contains motor representations of learned skills, is "directly responsive to higherorder, personal-level goals" (2017a, p. 1557).

Fridland explains this responsivity in terms of "cognitive penetration." According to her, there is a continuous "meaningful or semantic interaction" between the content of the motor and goal-representations through skill execution. It is because motor representations are cognitively penetrable, she concludes, that "the motor control involved in skilled action is intelligent all the way down" (2017a, p. 1541). Thus, Fridland contends that cognitive control requires the interaction between motor representations and goal-representations or intentions, which are encoded in a propositional form (see Pacherie \& Mylopoulos, 2020 for a similar claim) ${ }^{5}$

\footnotetext{
${ }^{5}$ Fridland (2017a, p. 1558) nonetheless acknowledges that her proposal suffers from the "interface problem." This is the problem of explaining how personal-level intentions, which are encoded in the forms of propositional states, can affect sub-personal motor representations, which are coded in a non-propositional way.
} 
Bermúdez (2017) disagrees that cognitive penetrability suffices for motor control and action selection. Rather, he proposes that "skilled action requires the deployment of effortful, top-down cognitive control processes whose function is to structure and coordinate multiple lower-level (perceptual, mnemonic, affective, motor) processes toward the attainment of the represented goal" (p. 901). Acting skilfully thus requires not only having personal-level goal representations, but keeping them in mind all the time. Therefore, he concludes, "a reflective, higherorder process must be invoked for the intelligence of skill" (p. 901). Also, unlike Fridland, Bermúdez denies that goals must be represented in a propositional format.

Another influential account of skilled action is "Mesh" (Sutton et al., 2011; Christensen et al., 2016, 2019; Christensen \& Sutton, 2019). Mesh is a "hybrid" theory that combines elements both from intellectualist and automatic theories of skilled motor behavior, and proposes "that controlled and automatic processes are closely integrated in skilled action, and that cognitive control directly influences motor execution in many cases" (2016, p. 43).

According to Christensen et al. (2016), one of the functions associated with cognitive control is the flexible integration of information about the situation, which, in turn, involves attentional control and cognitive interpretation. The driving idea of Mesh is that cognitive control is not eliminated in advanced skill, but rather that "skill learning produces cognitive structures that are well organized for the demands of the task, reducing the cognitive effort needed for effective higher order action control" (p. 50). As the performer becomes more skilled, it develops both a better interpretation of the performance situation and an associated action "gist" that specifies "not just an action type by also a particular way of performing the action appropriate to the circumstances" (p. 43). Being equipped with such action gist permits some degree of automation of the lower-level features associated with motor control, while the agent's conscious attention can now be directed to detect new information that serves to revise the previous interpretation of the situation. Mesh therefore conceives a broadly hierarchical division of responsibilities where cognitive control:

makes a vital contribution to skill control by determining the nature of the situation and configuring and adjusting lower order sensorimotor processes appropriately. Cognitive and automatic processes thus characteristically operate together in an intimately meshed arrangement, with cognitive control typically focused on strategic task features and automatic control responsible for implementation. (p. 62)

Even though Christensen, Sutton and colleagues explicitly align with extended, embodied and embedded accounts of cognition, they conceive of Mesh in strictly representational terms. According to Mesh, as skills get refined, the cognitive processes employed in the control of skill action come to "reflect in increasingly intimate ways the structure of bodily interaction [and] incorporate increasingly rich representations of bodily interaction" (Christensen \& Sutton, 2019, p. 160; see also Christensen et al., 2019, p. 708). Moreover, although they agree with Bermúdez (2017) that the mental representations implied in cognitive control "are often modelbased rather than language-like" (2019, p. 160), they suggest that "attention to the 
nature of skilled action in complex, real-world conditions can inform conceptions of cognitive representation and processes" (p. 161). ${ }^{6}$

As we can see, all the previous authors agree that to account for the intelligent control involved in skilled motor behavior we have to posit cognitive representations that influence, in a top-down fashion, motor execution. ${ }^{7}$ However, a careful examination of the texts shows that the only justification for this comes from the assumption that without mental representations, all we have left in terms of explanatory resources are inflexible stimulus-response associations. This assumption is made clear by Christensen and Sutton (2019; see also Levy, 2017; Pacherie \& Mylopoulos, 2020), for whom "[t]he question of whether skill automates can be thought of as a question as to whether advanced skills are representation-hungry" (p. 159). According to them, the fact that skilled motor behavior does not reduce to blind, reflex-like automatisms implies that it needs to be accounted for in terms of representational cognitive processes. Similarly, Ericsson argues that "expert performers counteract automaticity by developing increasingly complex mental representations to attain higher levels of control over their performance" (2006, p. 685).

We finished the previous section agreeing with Sutton et al. (2011) that the assumption that any action that is not automatic and reflex-like must be the result of slow, effortful planning and conscious ratiocination is unwarranted. We now claim that the authors reviewed in this section fall into another unjustified dichotomy: If an action is not blindly automatic, it must be caused by some representational cognitive process. To counter this view, in the following two sections we sketch an outline for a non-representational theory of skilled motor behavior that avoids blind automatism. We do so by drawing from the ecological theory of perception and action (Gibson, 1979[2015]) and the Deweyan (1922[2007]) theory of habits. Our thesis is that by combining them, we can build a theory of skilled action that does not assume that intelligent, skilful behavior is necessarily representation-based.

\section{Skilled action without representations}

Building upon the work done in the previous section, we claim that the challenge for a radical embodied theory of skilled motor behavior is to explain intelligent, cognitive control over action without assuming the existence of top-down representational processes. In this section, we argue that ecological psychology (Gibson, 1979[2015]; Chemero, 2009; Turvey, 2018; Segundo-Ortin et al., 2019) offers valuable conceptual, empirical, and methodological resources to start facing this challenge.

\footnotetext{
${ }^{6}$ Christensen et al. (2019) argue that "mental models can support the efficient construction of situation-specific responses. [...] Visuospatial mental models, in particular, have an apt format for controlling actions in a complex environment, which, for instance, might involve multiple objects and interactions" (p. 713).

7 According to Levy (2017), whereas it is evident that skilled action involves representations, it is "an open empirical question whether there are some cases of which intellectualism is true" (p. 524).
} 


\subsection{An ecological approach to skilled action}

A foundational idea of ecological psychology is that perception is direct. To say that perception is direct is to say that perception is not mediated by internal inferences or computations. Rather, perception consists of the detection (or "picking up") of perceptual information. To better understand this idea, we shall elaborate upon the notion of "perceptual information."

For ecological psychology, perceptual information is contingent on the existence of spatial-temporally extended and structured patterns in the topology of the ambient energy array (Lobo et al., 2018). Imagine a room illuminated by a ceiling light. As the light interacts with the surface of the objects that furnish the room, it generates a specific pattern - an ambient optic array. This pattern is not random or stochastic. Rather, it is lawfully generated given the conditions of the light and the objects - their situation, orientation towards the source of light, but also the materials they are made of. Ecological psychologists refer to the lawful relation that exists between the environmental properties and the ambient energy distribution as "specificity." To say that the ambient optic array is specific to the surfaces of the room is to say that there is a one-to-one covariation between the former and the latter. ${ }^{8}$ Because a particular surface $\alpha$ in the room lawfully generates a specific pattern $\beta$ in the ambient optic array, the occurrence of $\beta$ guarantees the presence of $\alpha$.

To fully appreciate the importance of specificity, it is worth remembering that the starting point of traditional (representational) theories of perception is the inability of light (or sound, or chemicals in the air, etc.) to specify their environmental causes. Because there is a many-to-one mapping of ambient patterns to environmental causes, perception necessitates "an almost unimaginably difficult causal inference problem: [brains] must infer the hidden state of the constantly changing environment from its profoundly non-linear and ambiguous effects on the organism's numerous sensory transducers" (Williams, 2018, p. 150). The necessity to explain this causal inference calls for a representational framework.

By contrast, the hypothesis of specificity denies that perceptual information is necessarily ambiguous and impoverished, thus parting with the necessity of a representational explanation for perception: If $\beta$ specifies $\alpha$, then detecting (paying attention to) $\beta$ suffices to perceive $\alpha$ :

Direct perception can be possible if properties of the world are specified in patterns of stimulus energy. If patterns of the world are unambiguously specified, perception does not have to involve processes of interpreting ambiguous cues. (Fajen et al., 2009, p. 81)

\footnotetext{
${ }^{8}$ As argued by Segundo-Ortin et al. (2019), once we understand specificity as covariation we see that this notion is free of any representational commitment.
} 
Thus, agents can be aware of the different properties of the performing situation by detecting information in the ambient array, but this awareness is not the product of mediating inferences and mental representations. ${ }^{9}$

Another foundational idea of the ecological approach is that perception is primarily for action. According to J. J. Gibson (1979[2015]), because the properties of the environmental setting are specified in the structure of ambient energy array, the agent can perceive what this setting affords to her by detecting this information. This implies that behavioral control is possible on the basis of direct perception, and that complex behavioral solutions that seem to require motor representations can be simplified by capitalizing on affordance-specific perceptual information:

[R] esearch shows that there is an alternative to appealing to such computational-representational structures and processes. With the right kind of information, an individual can be coupled to her task environment in a way that supports behaviour about forthcoming events without explicit predictions. (Silva et al., 2019, pp. 55-56)

For illustration, consider the perceptual-motor problem of breaking the car before crashing an approaching obstacle. Knowing the time remaining until physical contact with the obstacle is crucial for doing this. The question is how we can know this time. One possible solution is to assume that we perceive several properties of the environment - say, the current distance to the obstacle, the speed to which we approach it, etc. - and somehow combine them to infer this time. The ecological answer is radically different. According to General Tau Theory (see Lee, 2009), as the distance between the object and the visual system reduces, the object "expands" on the visual field, and the rate to which the object expands-a variable referred to as "tau" $(\tau)$ - specifies the time remaining until contact. ${ }^{10}$ Because the object's rate of expansion specifies time-to-contact, it provides the information needed to control action.

The empirical evidence speaks in favor of the ecological hypothesis. For instance, Fajen and Devaney (2006) successfully predicted that drivers stopping at designated points continuously adjust their breaking to keep $\tau_{\mathrm{x}}(t)$ - this is, the rate of change of $\tau$ over time-below 0.5 , the critical point at which avoiding collision is no longer afforded. After having compared different hypotheses, Fajen and Devaney concluded that drivers adjust braking on a moment-by-moment basis by detecting $\tau_{\mathrm{x}}(t)$. Braking is thus controlled by paying attention to $\tau_{\mathrm{x}}(t)$ without the necessity of forming and manipulating a mental model of the situation.

Strikingly, these studies also show that whereas perceivers are bad at estimating the distance to the object and the speed at which it approaches, they can successfully tell the moment at which avoiding collision is no longer possible. This supports the hypothesis that the primary objects of perception are the affordances and shows

\footnotetext{
9 Although and Gibson (1979[2015]) claims that perception involves awareness of the environment (p. 244), he is clear that perceptual awareness is not reflective (p. 249).

${ }^{10}$ Tau is defined as "the ratio of the optical size [of the approaching object] to the rate of optical expansion [of the same object during time]" (Jacobs \& Michaels, 2007, p. 324).
} 
how perception can guide action without mediating inferences. If all the information needed to control action-that is, the information needed to know whether avoiding collision is possible at this rate of deceleration-is already present in the ambient optic array, then calling upon representations to explain action control is unnecessary. ${ }^{11}$ Cognitive control over action can be achieved on the basis of direct perception.

\subsection{Perceptual learning for skilled action}

If successful perception-action coupling depends on detecting perceptual information, then it makes sense to conclude that "the strength of the coupling depends on the usefulness of the variable detected" (Withagen \& Chemero, 2012, p. 532). This claim invites the view that perception must be trained and learned.

Along with the study of perceptual processes, another branch of ecological psychology, mostly led by Eleanor Gibson (Gibson, 1969; Gibson \& Pick, 2000), has focused on studying how perception-action is trained-i.e., how perceivers get to detect new and better informational variables, thus improving overall performance. Ecological psychologists challenge the assumption that perceptual, or rather perceptual-motor, learning requires increasingly refined representations, and propose, instead, that it consists of attuning to more specific informational patterns. Therefore, according to ecological psychologists, the main factors that explain the difference between novices' and experts' performances in a particular task are the informational variables they use for guiding their action.

Perceptual learning is primarily depicted as involving the "education of attention." Attention is said to be optimally educated when the perceiver comes to detect the most useful (the most specific) informational variable for the task being faced. Once the right information is detected, the perceiver must calibrate her behavior to achieve the most efficient perception-action coupling-for example, by modifying the force applied to the braking pedal in response to $\tau_{\mathrm{x}}(t) .{ }^{12}$

Jacobs and Michaels (2007; see also Higueras-Herbada et al., 2019) have depicted perceptual learning as a direct process akin to perception. The theory of direct learning rests on the hypothesis that there is information in ambient energy arrays that is specific to the possibility of reducing non-optimalities in perception-action cycles. Jacobs and Michaels refer to this type of information as "information for learning" and claim that this information is present in the observable changes of the ambient array the learner produces when she acts. According to this theory, perceptual feedback following action provides information for learning, and detecting this

\footnotetext{
11 Ecological perceptual information is also defined as information of "what-leads-to-what" (Turvey, 2018 , p. 412). The idea is that the very structure of currently available information is lawfully linked to future states, hence allowing for anticipation without inferences or predictions. In the case of $\tau$, the future state is optically specified given the ratio of the optical size to the rate of optical expansion, thus allowing for anticipation and prospective control.

12 "Calibration refers to the process that establishes an appropriate scaling of information to perception or action" (De Vries et al., 2015, p. 1396). The term 'calibration' refers to the engagement of organism and environment via ecological information.
} 
information is tantamount to perceive how to improve the performance in successive trials. $^{13}$

The theory of direct learning has been successfully applied to investigate the learning of different skills, from simple ones such as keeping the balance of an inverted pendulum attached to a moving cart (Jacobs et al., 2012) or the identification of different object properties by dynamic touch while blindfolded (Jacobs et al., 2009), to more difficult ones, including practicing the final approach phase in landing via a flight simulator (Huet et al., 2011). All these studies show that, after practicing with sensory feedback, novices and experts tend to converge towards the same informational variables and use these variables to improve their performance. This suggests that "the assembly of functional actions in skilled performance is a dynamical process, dependent on relevant sources of perceptual information" (Davids et al. 2013, p. 24).

Hence, whereas traditional ecological studies have focused on formulating laws that connect perception (information for affordances) with action in specific tasks, detailing "which features of the action environment the [expert] agent is attending and why" (Fridland, 2014, p. 2736), studies on perceptual learning explain how agents can improve their perception-action in these tasks without assuming they must build increasingly sophisticated internal models of the environment. The experimental evidence gathered by ecological psychologists supports the idea that novice participants become experts as they educate their attention towards more specific information (see Higueras-Herbada et al., 2019 and Lobo et al., 2019 for a review). The learning curve predicted in task-specific direct learning studies is critical to explain how perceptual learning occurs in a non-representational way.

Directly connected to the issue of perceptual learning is decision-making. Decision-making is a clear example of agentive control, and, as such, it is commonly assumed to depend on mental inferences and represented action plans (see Fridland, 2017a, 2017b). The Gibsonian literature suggests a different picture. For instance, Araujo and colleagues (Araújo et al., 2006, 2019) have applied a broadly Gibsonian framework to study decision-making in sport performance. Their approach is based on previous work by Warren (2006). Warren developed a general explanatory framework for behavioral dynamics, articulated in terms of the emergence of behavior trajectories from informational, bio-mechanical, and task constraints. In this model, agent and environment are conceived of as a pair of dynamical systems coupled by perceptual information. According to it, the confluence of the biomechanics of the (neural and non-neural) body, the structure and physics of the environment, and the available perceptual information, all of them intertwined under the boundary conditions of a particular task or goal, give rise to adaptive, intelligent behavior. Decision-making - this is, changing from one type of action to another-is thus based on the continuous exploration and detection of competing variables in the information space of the task.

\footnotetext{
13 Presumably, changes on the relation with the external information are accompanied by changes at the physical, musculoskeletal, and neural level too (Jacobs \& Michaels, 2007, p. 341; see also Raja, 2019).
} 
As Raab and Araujo (2019) comment, when Warren's behavioral dynamics is applied to studying sports, we find out that "decision-making emerges as athletes search in a field of affordances to arrive at a stable, functional solution" (p. 6). This idea is exemplified by Correia et al. (2012). The authors used a VR environment to simulate a 3 vs. 3 rugby task where participants had to decide between running ahead with the ball, making a short pass to a teammate, or making a long pass. Participants were exposed to different scenarios, with the most important variable being the initial distance between the opponents, themselves, and the teammates. Experimenters found that participants used information regarding the opening paths to decide how to act, and that the emerging gaps relative to the defenders, and between the defenders and the teammates, were the best predictor of the carrier's behavior. In conditions where no gap was available, the participants most common solution was to keep the ball and wait until a sufficiently large gap emerged - that is, they waited until a better affordance appeared. For the authors, this suggests that "the action most often selected for each gap location was the affordance that was best aligned with the task goals" (p. 317). Besides, the researchers found out that "professional players were better able to distinguish the information specifying the affordance in each of the varying gap conditions" (p. 318). ${ }^{14}$

What these empirical findings suggest is that decision-making is a dynamical process influenced by the availability and detection of affordances. Decisions occur at so-called "bifurcation points" when new information appears, and ultimately depend on the capacity of the athlete to detect this information. Decisions are made by means of perceiving better affordances. Moreover, because experts can detect more specific informational variables than the novices, then they have a higher capacity to appropriately modify their actions according to the circumstances. This explains why behavioral flexibility increases with perceptual skill, and shows that perceptual learning is crucial for improving decision-making in skilled performance.

\subsection{Considering different objections}

Before concluding this section, there are two potential objections that deserve consideration. To begin with, it can be argued that some claims by Gibsonian psychologists invite the reading that skilled is passive. For instance, Correia et al. (2012) assert that the information available at each stage of the task "is shaping the emerging actions" (p. 317). Likewise, Withagen et al. (2012) have argued that agents can be attracted or repelled by the affordances of the environment to act in specific ways. At first glance, this can possess a problem for us, for it invites the reading that action are drawn by the affordances and so that it is not under the agent's control.

We argue that this is a too simplistic reading of the situation (see Segundo-Ortin, 2020). In particular, such a reading overlooks the fact that for affordances to attract or repel action they have to be perceived, and perception is in itself an active process according to ecological psychology. In fact, in The ecological approach to visual

${ }^{14}$ For similar studies see Esteves et al. (2011) and Travassos et al. (2012). 
perception, J. J. Gibson (1979[2015]) urged for a redefinition of perception as "an achievement of the individual" (p. 228) and often spoke about the "act of perceiving" (p. 130) ${ }^{15}$ For one thing, he depicted perception as an act information pickup, not a response to a stimulus. This implies that to perceive an affordance, the observer must modulate her attention, selecting ("picking up") the informational variables that are relevant for the goal she aims to achieve. Moreover, perceptual acts often involve more than shifting our attention focus; they require skillfully exploring and manipulating the environment in order to generate the appropriate information. ${ }^{16}$ Both kinds of exploratory activity are under the control of the agent and are necessary in order to perceive affordance. Therefore, even if affordances were shown to invite, solicit, or attract action in any way (but see Heras-Escribano, 2019a, 2019b, p. 111 for a critique of this hypothesis), this would not imply that the whole perception-action process is passive.

The idea that perception-action is active and goal-oriented invites the second worry. For representationalists, it is not clear how we can explain the goal-directed character of perception-action without assuming that goals are represented in the agent's mind and influence, in a top-down fashion, perception and action. Before we deal with this objection, it is noteworthy that neither Fridland (2017a, 2017b) nor Bermudez (2017) offer reasons as to why goal-directedness requires discrete goal-representations. Instead, they simply assume this to be the case and focus their analysis on determining the format these representations must take. Moreover, they do not even explain how such goal-representations intervene in controlling attention and motor processes.

Fortunately, this is not the only option available. Defenders of radical embodied theories of cognition have offered different strategies to account for goal-directedness without assuming that there must be a part of the system-the goal-representation-that controls and shapes the system's overall behavior (see Brancazio \& Segundo-Ortin, 2020; Di Paolo et al., 2017; Reed, 1996). We will focus here on a proposal first articulated by Juarrero (1999) and later explored by Van Orden and colleagues (Van Orden et al., 2003) in the context of ecological psychology. The core idea is that intentional actions are not the products of discrete, causally efficacious mental states. Instead, they emanate from the self-organizing dynamics of open dynamical systems that span the brain, body, and environment. Open systems exchange matter and energy with their environment through a process of feedback loop. Thanks to this positive feedback loop, the agent affects the environment and is affected by it, shaping a common dynamical trajectory. This feedback loop gives rise to the sort of self-control that, according to Juarrero, is characteristic of purposive, goal-oriented behavior.

\footnotetext{
15 Besides, in the initial paragraphs of this book, Gibson (1979[2015], p. 1) claims that "psychology begins with the division between the inanimate and the animate", showing how the psychological is dependent on action.

${ }^{16}$ A clear example of this are the experiments on "effortful touching" (Turvey \& Carello, 2011). These experiments show that some perceptual tasks require the active manipulation of the environment by the observer.
} 
According to Juarrero's view, committing to one goal does not involve forming a discrete mental representation. Instead, it implies entering a specific selforganized neural and non-neural configuration that, in turn, sets the whole system, at different physical and temporal scales, near a critical state. Critical states are those in which the system is acutely sensitive to the contextual factors that are directly relevant to the consecution of the goal, making some motor behaviors more likely to occur than others. On this view, goal-directed actions are to be understood as "dynamical trajectories" (Juarrero, 1999, p. 150) instead of as the product of discrete mental representations.

Ecological psychologists understand the previously mentioned feedback loop in terms of perception and action, and take the information about affordances as the main currency in this exchange:

Action changes the circumstances of the mind and body, which change the opportunities for perception [...]. Changing propensities for action introduce new opportunities for perception. New opportunities for perception entail new propensities for action and reconfigure intentional contents. This interplay among self-organizing intentional contents and perceptually changing circumstances uniquely situates ordinary purposive behavior. (Van Orden et al., 2003, p. 333)

This idea fits well with what the ecological literature about decision-making in sport shows (see, e.g., Correia et al., 2012). Being tasked with not losing the ball to the opponent makes participants more acutely sensitive to the affordances relevant to this task. However, as the situation changes, new affordances emerge, biasing the behavior of participants toward other, more specific goals-namely, running forward instead of passing the ball to a teammate. Importantly, the intention to run forward was not there before the situation changed, but emerged once the agent perceived that passing the ball to a teammate was no longer possible. Therefore, acting intentionally does not require keeping a goal in mind, but exploiting the goal-specific information present in the ambient array.

Moreover, we believe that adopting this dynamical approach helps us make sense of recent empirical discoveries concerning the neural underpinnings of action control. Uithol et al. (2014) conducted a review of different studies concerning the activity of the lateral prefrontal cortex (IPFC) - the area of the brain that is generally recognized to be responsible for engendering and controlling action-while participants were engaged in different motor control tasks. According to the authors, all the evidence shows that the activity in the IPFC is highlycontext sensitive, making it impossible to track one specific state or firing pattern that remains stable, guiding action from beginning to end:

[I]n contradiction to the condition of positing discrete representations, the activation of the neurons [within the IPFC] do in fact vary continuously during the period of action control, and moreover in a way that is sensitive to the fine-grained temporal progression of the action sequence. (Uithol et al., 2014, p. 133) 
For the authors, the fact that the patterns of activation in the 1PFC are continuously modified through action execution "speaks against the idea of a discrete state that begins the action coordination process, and retain its functional identity and content through an action episode" (p. 133; see also Kalis, 2019). This, the authors conclude, undermines the idea that goal-oriented behavior involves the top-down influence of goal-representations over motor control processes. For them, "the idea of a discrete intention causing and controlling actions from the top of a representational hierarchy is a mischaracterization of the complex and dynamic nature of action control" (p. 136).

Advancing a thorough account of purposive behavior in non-representational terms is beyond the scope of this paper. Instead, we want to argue that the fact that there are alternatives to representational accounts of intentional or goal-directed behavior, united to the traditional problems associated with the idea that representational contents can cause motor behavior, and the previously mentioned difficulties in finding neural states that can be identified with goal-representations, show that the view that goal-representations are required for goal-directedness is far from evident. Therefore, an argument must be forthcoming on the representationalists' side before we can accept their claim as a matter of fact.

\section{The importance of habits for an ecological theory of skilled motor behavior}

In the previous section, we have argued that ecological psychology offers a theoretical and experimental framework that allows us to understand how skilled action can be intelligent (context-sensitive, under control) without mental representations. If perceptual information is specific to the affordances of the environment, agents can control their performance by detecting these informational variables. To do so, agents must learn how to "attune" their attention and explore the information available in the task setting.

Nevertheless, despite the immense amount of empirical evidence gathered by ecological psychologists, we argue that the ecological framework lacks an essential element for offering a full-blown account of skilled performance. One widely noted aspect in the literature of skilled performance is that even though skill learning excludes full automation, it involves a significant decrease in the amount of cognitive effort needed to perform some skilled actions. Christensen et al. (2016) capture this idea when they say that "skill learning produces cognitive structures that are well organized for the demands of the task, reducing the cognitive effort needed for effective higher order action control" (p. 50). As we saw before, these cognitive structures are characterized as mental representations of different types.

Our aim in this section is to account for the cognitive dimension of skilled motor behavior in a way that is consistent with the ecological approach we have been defending in this paper. Against the representational view, our claim is that formulating a non-representational account of intelligent, skilled motor behavior requires that we properly understand how habits interact and merge with the direct 
perception of affordances. The remaining of this section is dedicated to fleshing out this proposal.

It is well recognized that a fundamental part of skill training consists of turning specific perception-action cycles into habits. Broadly speaking, we understand habits as task-related dispositional perceptual-motor sequences that are executed with less cognitive effort than other perception-action cycles. Once the expert has incorporated these habits, she can respond and adapt to the environment in a more efficient way than novices.

There are, however, different notions of "habit" at play in the cognitive science literature. Barandiaran and Di Paolo (2014) distinguish between two general trends: "associationism" and "organicism." According to the former, habits are rigid, subpersonal behavioral routines that are automatically triggered in the presence of the right cues. The second trend, "organicism," is more in line with current theories of embodied cognition (see Di Paolo et al., 2017). As opposed to being the passive result of the recurrence of pre-established stimulus-response associations, habits in the organicist tradition "are examined along what we would call today more ecological, self-organizing lines [and] are also related to a plastic equilibrium that involves the totality of the organism, including other habits, the body and the habitat they codetermine" (p. 5).

A number of authors have already introduced the organicist notion of habit into the discussion of skilled motor behavior. For instance, Hutto and Robertson (2020) point out that because all habits take place in an environment that is anything but static, habitual doings must be adaptive, flexible, and selective. Hence, they argue, "it is a mistake to contrast habits with skilful doings because we may [...] do skilful things habitually" (p. 209). Similarly, Gallagher and Varga (2020) claim that practice "tunes motoric organization to the point where it can become habitual" (p. 5). They nonetheless reject associationism and contend that the expert's habits "are already context sensitive, anchored in the situation, but at the same time smart, open, and adaptive" (ibid.; see also Cappuccio \& Ilundáin-Agurruza, 2020).

Even though Barandiaran and Di Paolo (2014) find the origins of this organicist notion of habit in Spinoza, we think that it is in Dewey's work where we find the clearest instance of this view (see Crippen \& Schulkin, 2020; Testa \& Caruana, 2020). Even though Deweyan habits have been previously proposed to be compatible with the principles of ecological psychology (see Heras-Escribano, 2019a, pp. 191-202, 2019b; Segundo-Ortin, 2020), our aim in this section is to show how this notion of habit can complement the ecological approach to skilled motor behavior we are defending. ${ }^{17}$

To fully grasp the notion of habit advanced by Dewey, it is important to start clarifying the relationship between acts and experience he envisaged. Dewey rejected the assumption that the experience of the world is given passively (1896; [1925]2000). Instead, he thought that every experience is already incorporated into an "act"namely, the act of looking, the act of reaching, and even the act of thinking — and

\footnotetext{
17 Merleau-Ponty is another crucial author for understanding the idea of organic habits (see Cappuccio \& Ilundáin-Agurruza, 2020).
} 
that these acts structure what is found in the world. According to Brinkman, this means that "for Dewey, the basic analytic unit in psychology becomes the goaldirected activity itself through which the organism tries to affect and change the stimuli that meets it" (2011, p. 306). He also believed that acts do not occur in isolation, but that we behave "with reference to a time-spread, a serial order of events" so that "what is done is conditioned by consequences of prior activities" (1925[2000], p. 279). Accordingly, acts structure how we experience the world, and this experience modulates subsequent actions.

Even though Dewey thought that practice was important to turn acts into habits, he did not take blind repetition to be the essence of habits. Rather, he characterized habits as "predisposition[s] formed by a number of specific acts" (1922[2007], p. 25). According to this view, habits consist of coordinated sequences of acts that "form our effective desires and furnish us with our working capabilities" (ibid.). That a series of acts form a habit thus means: (1) that they are linked as a sequence, and (2) that we are predisposed to enact them. Also, in line with the idea that acts structure our experience of the world, he claims that " $[\mathrm{t}] \mathrm{he}$ essence of habit is an acquired predisposition to ways or modes of response [...]. Habit means special sensitiveness or accessibility to certain classes of stimuli, standing predilections and aversions, rather than bare recurrence of acts" (p. 42). Series of perception-action cycles - "acts" in the vocabulary of Dewey-become integrated as habits when one cycle leads to the next one in the form of a tendency or disposition.

We contend that the Deweyan notion of habit as structured predispositions of perception-action cycles can contribute to an ecological theory of skilled action in multiple ways. First, consider the role that habits play in perception. According to Dewey "[t]he medium of habit filters all the materials that reaches our perception" (1922 [2007], p. 32). Framing Dewey's idea in the context of ecological psychology, we propose that some habits consist of exploratory patterns that allow us to detect informational variables. Hence, we hypothesize that part of perceptual learning consists of developing efficient habits of exploration that allows the agent to detect specific information better than novices.

As aforementioned, perceptual learning is primarily accomplished via de education of attention. Yet, besides learning what informational variable to attend in order to accomplish a particular task, the agent must also learn how to explore the environment in order to find this information. This second aspect is crucial, for this perceptual exploration can be done in more and less efficient ways. For instance, Savelsberg et al. (2002) studied visual search behavior in novice and expert goalkeepers trying to anticipate the direction of a penalty kick and determined that while the novices spent longer paying attention to the trunk, arms, and hips of the kickers, expert goalkeepers used a more efficient search strategy, focusing their attention on the position of the legs at the moment of foot-ball contact. Experts not only were better at anticipating the direction of the penalty kicks but showed "more refined and selected visual search patterns" (p. 283). In the case of a goalkeeper, not having a refined search pattern means taking more time to initiate movement, and sometimes being unable to anticipate the direction of the ball. Likewise, experiments on dynamic touch show that after several trials, perceivers develop more refined search strategies that allow them to perceive 
particular affordances of objects with less but more precise torques (Jacobs et al., 2009; Wagman et al., 2001).

The filtering function of Deweyan habits fits very well with the education of attention. When novices learn to perceive, they must develop exploratory patterns for detecting more specific information. The education of attention is thus achieved in part thanks to the refinement of exploratory patterns, as these patterns include orientations, positions, and movements that directly affect the attention focus of the perceiver (Gibson, 1988; Reed, 1996). By turning these more refined exploratory patterns into habits, experts can detect the relevant information with less effort than novices. Paraphrasing Miyahara and Robertson (in press.), we claim that what we call 'exploratory habits' "promote intelligent behavior by constraining the range of possible [exploratory] actions at the level of perception" (p. 27).

Another important aspect of Deweyan habits is the idea that habits are a source of intentional, goal-directed behavior. Dewey is explicit on this view when he claims that habits "are demands for certain kinds of activities [...] they are will" (1922[2007], p. 25). If habits predispose us to act in certain ways, then consolidating perception-action cycles into habits is a useful way to simplify and optimize decision-making processes.

To see this point more clearly, think of a novice squash player. A common problem that all amateur players face is having to come back to the center of the field after each stroke. Occupying the center of the field is essential, for it implies that all runs are affordable. At the beginning, however, this requires a considerable effortthe novice must constantly remind herself to do it. In addition, because the novice's attention is mostly focused on forcing herself to come back to the center, she is unaware of other relevant aspects of the situation. With practice, the squash player can incorporate this act into her behavioral repertoire in the form of a habit. Linking this 'returning act' to each executed stroke in the form of a habit or a dispositional sequence reduces the need for conscious attention to this specific activity. Crucially, this frees the player's attention focus to perceive other relevant affordances of the situation-namely, the position of the opponent in the field, the presence of a gap that affords scoring, etc.

Hence, we hold that the Deweyan notion of habit can help us understand how skillful, intelligent performance is structured as different kinds of perceptual-motor disposition that are deployed to satisfy the agent's needs and goals. Dewey nonetheless distinguished between "routine" and "intelligently controlled" habits. This distinction is not absolute but dialectical, meaning that the same habit can exhibit both features in different situations (Testa, 2017). Whereas routine habits are characterized as rote, inflexible, and stereotyped mechanical drills that are automatically triggered by previous cues, intelligent habits are characterized for being both self-preserving and self-transforming. Intelligent habits, Dewey claims, are open and context-sensitive - they imply not only reaction, but adaptation to the environment. This is emphasized by contemporary authors who claim that skilled or intelligent habits are "context sensitive [and] anchored in the situation" (Gallagher \& Varga, 2020, p. 5). The challenge, however, is to explain what "anchors" habits in the situation. 
To explain this, we draw from the work done in the previous section and propose that a way to preclude habits from becoming mechanical drills, keeping them under control, is paying conscious attention to the affordances of the environment. ${ }^{18}$ It is because the agent is not acting on autopilot but constantly searching for new information for affordances that she can control her behavior, adapting previously learned habits to the new, particular circumstances. For instance, if the squash player realizes that her opponent has the tendency of sending the ball to the right side of the field, she will run to this side after each stroke, instead of running back to the center. This is the opposite of letting a previously acquired reflex run on its own, but it does not require that the agent stops and thinks. Rather, the perception of a new affordancethe possibility of scoring more points when she is on the right part of the fieldsuffices for the expert to adapt her habitual playing style to the here-and-now. This adaptability can occur in longer timescales too. For instance, we saw that perceptual feedback after each trial led agents to realize that there are more efficient strategies to perceive a particular affordance, refining their previously acquired searching habits (Wagman et al., 2001). These variations on previous searching habits are possible because the agent has detected new information about affordances. We hold this is consistent with Dewey's claim that we can adjust our habits "by an intelligent selecting and weighting of the objects which engage attention" (1922[2007], p. 20). In our picture, the objects of attention are the affordances.

In sum, our proposal is that learning a motor skill partly depends on developing and acquiring the right sort of embodied habits, whereby habits are understood as organized, context-sensitive, dispositional sequences of mutually coherent perception-action cycles that remain anchored in the situation via the direct perception of affordances. Habits become routine, in the sense of Dewey, when the agent is performing with little or no attention to what the situation affords. So, against claims that "a truly unreflective control is possible because of and effected through habits" (Cappuccio \& Ilundáin-Agurruza, 2020, p. 155), we believe that control is achieved when habits are complemented by the agent's conscious attention to the affordances of the environment. It is not mental representations but the direct perception of affordances what anchors habits to the world, precluding them from becoming rote mechanical drills, and making skilled motor performance possible.

\section{Conclusion}

In this paper, we have defended a radical embodied approach to skilled motor behavior. The assumption in the literature is that any action that is not blindly automatic and mechanical must be caused by cognitive representations. To counter this

\footnotetext{
18 We do not claim this is the only option. Another possibility would be to consciously reflect about our habits. For a proposal of how to integrate conscious reflection and habitual behavior see Gallagher (2017). Strikingly, Gallagher proposes "to think of mental skills such as reflection, problem solving, decision-making, and so on, as enactive, non-representational forms of embodied coping that emerge from a pre-predicative perceptual ordering of differentiations and similarities" (p. 215).
} 
assumption, we have offered an account that brings together the ecological theory of perception and action and the Deweyan theory of habits. From an ecological perspective, perception and action are coupled via the direct detection of perceptual information. Because this information specifies the affordances of the environment, an agent can control its behavior by relying on such information. Moreover, if perceptual information is specific to the affordances of the environment, agents can increasingly control their performance by coming to detect more useful (more specific) informational variables. Second, we have argued that the Deweyan theory of habits, understood as organized, context-sensitive, dispositional sequences of mutually coherent perception-action cycles, shows how skillful performance can be structured as different kinds of dispositions and sets of exploratory repertoires that are deployed to satisfy the agent's goals, being these dispositions anchored in the situation thanks to direct perception.

We argue that by combining ecological psychology with the Deweyan theory of habits we can provide a radical embodied, non-representational account of skilled motor behavior that sits in the middle of mindful (intellectualist) and mindless (automatic) approaches.

Acknowledgements MSO and MHE are grateful to Annemarie Kalis, Josephine Pascoe, Eline de Groot, Rebecca Zeilstra, and two anonymous reviewers for their useful comments and suggestions. MSO's research for this article was supported by the Australian Research Council Discovery Project "Mind in Skilled Performance" (DP170102987) and the Nederlandse Organisatie voor Wetenschappelijk Onderzoek VIDI Research Project "Shaping our action space: A situated perspective on self-control" (VI. VIDI.195.116). MHE has written this paper thanks to a 2018 Leonardo Grant for Researchers and Cultural Creators, BBVA Foundation (The Foundation accepts no responsibility for the opinions, statements and contents included in the project and/or the results thereof, which are entirely the responsibility of the authors), and the research projects FFI2016-80088-P and PID2019-109764RB-I00 funded by the Spanish Ministry of Science, and the FiloLab Group of Excellence, University of Granada (Spain).

Open Access This article is licensed under a Creative Commons Attribution 4.0 International License, which permits use, sharing, adaptation, distribution and reproduction in any medium or format, as long as you give appropriate credit to the original author(s) and the source, provide a link to the Creative Commons licence, and indicate if changes were made. The images or other third party material in this article are included in the article's Creative Commons licence, unless indicated otherwise in a credit line to the material. If material is not included in the article's Creative Commons licence and your intended use is not permitted by statutory regulation or exceeds the permitted use, you will need to obtain permission directly from the copyright holder. To view a copy of this licence, visit http://creativecommons.org/licen ses/by/4.0/.

\section{References}

Araújo, D., Davids, K., \& Hristovski, R. (2006). The ecological dynamics of decision making in sport. Psychology of Sport and Exercise, 7(6), 653-676. https://doi.org/10.1016/j.psychsport.2006.07.002

Baggs, E., Raja, V., \& Anderson, M. L. (2020). Extended skill learning. Frontiers in Psychology, 11, 1956. https://doi.org/10.3389/fpsyg.2020.01956

Barandiaran, X. E., \& Di Paolo, E. A. (2014). A genealogical map of the concept of habit. Frontiers in Human Neuroscience. https://doi.org/10.3389/fnhum.2014.00522 
Bermúdez, J. P. (2017). Do we reflect while performing skillful actions? Automaticity, control, and the perils of distraction. Philosophical Psychology, 30(7), 896-924. https://doi.org/10.1080/09515089. 2017.1325457

Brancazio, N., \& Segundo-Ortin, M. (2020). Distal engagement: Intentions in perception. Consciousness and Cognition, 79, 102897. https://doi.org/10.1016/j.concog.2020.102897

Breivik, G. (2007). Skillful coping in everyday life and in sport: A critical examination of the views of Heidegger and Dreyfus. Journal of the Philosophy of Sport, 34(2), 116-134. https://doi.org/10. 1080/00948705.2007.9714716

Brinkmann, S. (2011). Dewey's neglected psychology: Rediscovering his transactional approach. Theory \& Psychology, 21(3), 298-317. https://doi.org/10.1177/0959354310376123

Cappuccio, M. L., \& Ilundáin-Agurruza, J. (2020). Swim or sink: Habit and skillful control in sport performance. In F. Caruana \& I. Testa (Eds.), Habits (pp. 137-162). Cambridge University Press. https://doi.org/10.1017/9781108682312.007

Chemero, A. (2009). Radical embodied cognitive science. Cambridge, Mass.: MIT Press, 2009.

Christensen, W., Sutton, J., \& Bicknell, K. (2019). Memory systems and the control of skilled action. Philosophical Psychology, 32(5), 692-718. https://doi.org/10.1080/09515089.2019.1607279

Christensen, W., Sutton, J., \& McIlwain, D. J. F. (2016). Cognition in skilled action: Meshed control and the varieties of skill experience. Mind \& Language, 31(1), 37-66. https://doi.org/10.1111/mila. 12094

Correia, V., Araújo, D., Cummins, A., \& Craig, C. M. (2012). Perceiving and acting upon spaces in a VR rugby task: Expertise effects in affordance detection and task achievement. Journal of Sport and Exercise Psychology, 34(3), 305-321. https://doi.org/10.1123/jsep.34.3.305

Crippen, M. (2017). Embodied cognition and perception: Dewey, science and skepticism. Contemporary Pragmatism, 14(1), 112-134. https://doi.org/10.1163/18758185-01401007

Crippen, M. (2020). Enactive pragmatism and ecological psychology. Frontiers in Psychology. https:// doi.org/10.3389/fpsyg.2020.538644

Crippen, M., \& Schulkin, J. (2020). Mind ecologies body, brain, and world. Columbia University Press.

Davids, K., Araújo, D., Vilar, L., Renshaw, I., \& Pinder, R. (2013). An ecological dynamics approach to skill acquisition: Implications for development of talent in sport. Talent Development \& Excellence, 5(1), 21-34.

Dewey, J. (1896). The concept of reflex arc in psychology. Psychological Review, 3(4), 357-370.

Dewey, J. (1922[2007]). Human nature and conduct. An introduction to social psychology. New York: Cosimo Books.

Dewey, J. (1925[2000]). Experience \& Nature. Dover.

Dewey, J. (1934[2005]). Art as experience. Perigee.

Di Paolo, E., Buhrmann, T., \& Barandiaran, X. (2017). Sensorimotor life: An enactive proposal. Oxford University Press.

Dreyfus, H. L. (2002). Intelligence without representation - Merleau-Ponty's critique of mental representation. Phenomenology and the Cognitive Sciences, 1(4), 367-383. https://doi.org/10.1023/A:10213 51606209

Dreyfus, H. L. (2006). Overcoming the myth of the mental. Topoi, 25(1-2), 43-49. https://doi.org/10. 1007/s11245-006-0006-1

Dreyfus, H. L. (2007a). Response to McDowell. Inquiry, 50(4), 371-377. https://doi.org/10.1080/00201 740701489401

Dreyfus, H. L. (2007b). The Return of the Myth of the Mental. Inquiry, 50(4), 352-365. https://doi.org/ $10.1080 / 00201740701489245$

Dreyfus, H. L. (2013). The myth of the pervasive of the mental. In J. K. Schear (ed.), Mind, reason, and being-in-the-world. The McDowell-Dreyfus debate (pp. 15-40). New York, NY: Routledge.

Ericsson, K. A. (2006). The influence of experience and deliberate practice on the development of superior expert performance. In K. A. Ericsson, N. Charness, P. Feltovich, \& R. R. Hoffman (Eds.), Cambridge Handbook of expertise and expert performance (pp. 685-706). Cambridge University Press.

Esteves, P. T., de Oliveira, R. F., \& Araújo, D. (2011). Posture-related affordances guide attacks in basketball. Psychology of Sport and Exercise, 12(6), 639-644. https://doi.org/10.1016/j.psychsport.2011. 06.007

Fajen, B. R., \& Devaney, M. C. (2006). Learning to control collisions: The role of perceptual attunement and action boundaries. Journal of Experimental Psychology: Human Perception and Performance, 32(2), 300-313. https://doi.org/10.1037/0096-1523.32.2.300 
Fajen, B. R., Riley, M. A., \& Turvey, M. T. (2009). Information, affordances, and the control of action in sport. International Journal of Sport Psychology, 40(1), 79-107.

Fridland, E. (2014). They've lost control: Reflections on skill. Synthese, 191(12), 2729-2750. https://doi. org/10.1007/s11229-014-0411-8

Fridland, E. (2017a). Skill and motor control: Intelligence all the way down. Philosophical Studies, 174(6), 1539-1560. https://doi.org/10.1007/s11098-016-0771-7

Fridland, E. (2017b). Automatically minded. Synthese, 194(11), 4337-4363. https://doi.org/10.1007/ s11229-014-0617-9

Gallagher, S. (2017). Enactivist interventions: Rethinking the mind. Oxford University Press.

Gallagher, S., \& Varga, S. (2020). Meshed architecture of performance as a model of situated cognition. Frontiers in Psychology, 11. https://doi.org/10.3389/fpsyg.2020.02140

Gibson, E. J. (1988). Exploratory Behavior in the Development of Perceiving, Acting, and the Acquiring of Knowledge. Annual Review of Psychology, 39(1), 1-42. https://doi.org/10.1146/annurev.ps.39. 020188.000245

Gibson, E. Jack. (1969). Principles of perceptual learning and development. Prentice-Hall.

Gibson, E. Jack, \& Pick, A. D. (2000). An ecological approach to perceptual learning and development. Oxford University Press.

Gibson, J. J. (1979[2015]). The ecological approach to visual perception. New York: Psychology Press.

Heras-Escribano, M. (2019a). The Philosophy of Affordances. Palgrave.

Heras-Escribano, M. (2019b). Pragmatism, enactivism, and ecological psychology: Towards a unified approach to post-cognitivism. Synthese. https://doi.org/10.1007/s11229-019-02111-1

Higueras-Herbada, A., de Paz, C., Jacobs, D. M., Travieso, D., \& Ibáñez-Gijón, J. (2019). The direct learning theory: A naturalistic approach to learning for the post-cognitivist era. Adaptive Behavior. https://doi.org/10.1177/1059712319847136

Hildebrand, D. (2018). John Dewey. In E. N. Zalta (Ed.), The Stanford Encyclopedia of Philosophy (Winter 2018). Metaphysics Research Lab, Stanford University. https://plato.stanford.edu/archives/win20 18/entries/dewey/

Høffding, S., \& Montero, B. G. (2020). Not being there: An analysis of expertise-induced amnesia. Mind \& Language, 35(5), 621-640. https://doi.org/10.1111/mila.12260

Huet, M., Jacobs, D. M., Camachon, C., Missenard, O., Gray, R., \& Montagne, G. (2011). The education of attention as explanation of variability of practice effects: Learning the final approach phase in a flight simulator. Journal of Experimental Psychology: Human Perception and Performance, 37(6), 1841-1854. https://doi.org/10.1037/a0024386

Hutto, D., \& Robertson, I. (2020). Clarifying the character of habits: Understanding what and how they explain. In F. Caruana \& I. Testa (Eds.), Habits: Pragmatist Approaches from Cognitive Science, Neuroscience, and Social Theory (pp. 204-222). Cambridge: Cambridge University Press.

Jacobs, D. M., \& Michaels, C. F. (2007). Direct learning. Ecological Psychology, 19(4), 321-349.

Jacobs, D. M., Silva, P. L., \& Calvo, J. (2009). An empirical illustration and formalization of the theory of direct learning: The muscle-based perception of kinetic properties. Ecological Psychology, 21(3), 245-289. https://doi.org/10.1080/10407410903058302

Jacobs, D. M., Vaz, D. V., \& Michaels, C. F. (2012). The learning of visually guided action: An information-space analysis of pole balancing. Journal of Experimental Psychology: Human Perception and Performance, 38(5), 1215-1227. https://doi.org/10.1037/a0027632

Juarrero, A. (2000). Dynamics in action: Intentional behavior as a complex system. MIT Press.

Lobo, L., Heras-Escribano, M. \& Travieso, D. (2019). The history and philosophy of ecological psychology. Frontiers in Psychology, 9. https://doi.org/10.3389/fpsyg.2018.02228

Lobo, L., Travieso, D., Jacobs, D. M., Rodger, M., \& Craig, C. M. (2018). Sensory substitution: Using a vibrotactile device to orient and walk to targets. Journal of Experimental Psychology: Applied, 24(1), 108-124.

Levy, N. (2017). Embodied savoir-faire: Knowledge-how requires motor representations. Synthese, 194(2), 511-530. https://doi.org/10.1007/s11229-015-0956-1

Miyahara, K., Ransom, T. G., \& Gallagher, S. (2020). What the situation affords: Habit and heedful interrelations in skilled performance. In F. Caruana \& I. Testa (Eds.), Habits: Pragmatist Approaches from Cognitive Science, Neuroscience, and Social Theory (pp. 120-136). Cambridge University Press. https://doi.org/10.1017/9781108682312.006

Montero, B. G. (2013). A dancer reflects. In J. K. Schear (Ed.), Mind, reason, and being-in-the-world. The McDowell-Dreyfus debate (pp. 303-319). New York, NY: Routledge. 
Montero, B. G. (2016). Thought in action: Expertise and the conscious mind. Oxford: Oxford University Press.

Pacherie, E., \& Mylopoulos, M. (2020). Beyond automaticity: The psychological complexity of skill. Topoi. https://doi.org/10.1007/s11245-020-09715-0

Papineau, D. (2013). In the zone. Royal Institute of Philosophy Supplement, 73, 175-196. https://doi. org/10.1017/S1358246113000325

Papineau, D. (2015). Choking and the yips. Phenomenology and the Cognitive Sciences, 14(2), 295-308. https://doi.org/10.1007/s11097-014-9383-x

Raab, M., \& Araújo, D. (2019). Embodied cognition with and without mental representations: The case of embodied choices in sports. Frontiers in Psychology. https://doi.org/10.3389/fpsyg.2019. 01825

Raja, V. (2019). From metaphor to theory: The role of resonance in perceptual learning. Adaptive Behavior. https://doi.org/10.1177/1059712319854350

Reed, E. (1996). Encountering the world: Toward an ecological psychology. Oxford University Press.

Savelsbergh, G. J. P., Williams, A. M., Kamp, J. V. D., \& Ward, P. (2002). Visual search, anticipation and expertise in soccer goalkeepers. Journal of Sports Sciences, 20(3), 279-287. https://doi.org/ $10.1080 / 026404102317284826$

Segundo-Ortin, M. (2020). Agency from a radical embodied standpoint: An ecological-enactive proposal. Frontiers in Psychology. https://doi.org/10.3389/fpsyg.2020.01319

Segundo-Ortin, M., Heras-Escribano, M., \& Raja, V. (2019). Ecological psychology is radical enough: A reply to radical enactivists. Philosophical Psychology, 32(7), 1001-1023. https://doi. org/10.1080/09515089.2019.1668238

Stanley, J., \& Krakauer, J. W. (2013). Motor skill depends on knowledge of facts. Frontiers in Human Neuroscience. https://doi.org/10.3389/fnhum.2013.00503

Sutton, J. (2007). Batting, habit and memory: The embodied mind and the nature of skill. Sport in Society, 10(5), 763-786. https://doi.org/10.1080/17430430701442462

Sutton, J., McIlwain, D., Christensen, W., \& Geeves, A. (2011). Applying intelligence to the reflexes: Embodied skills and habits between Dreyfus and Descartes. Journal of the British Society for Phenomenology, 42(1), 78-103. https://doi.org/10.1080/00071773.2011.11006732

Testa, I. (2017). Dewey, second nature, social criticism, and the Hegelian heritage. European Journal of Pragmatism and American Philosophy, IX(IX-1). https://doi.org/10.4000/ejpap.990

Testa, I. (2020). A habit ontology for cognitive and social sciences: Methodological individualism, pragmatist interactionism, and 4E cognition. In F. Caruana \& I. Testa (Eds.), Habits (pp. 395416). Cambridge University Press. https://doi.org/10.1017/9781108682312.020

Todorov, E., \& Jordan, M. I. (2002). Optimal feedback control as a theory of motor coordination. Nature Neuroscience, 5(11), 1226-1235. https://doi.org/10.1038/nn963

Travassos, B., Araújo, D., Davids, K., Vilar, L., Esteves, P., \& Vanda, C. (2012). Informational constraints shape emergent functional behaviours during performance of interceptive actions in team sports. Psychology of Sport and Exercise, 13(2), 216-223. https://doi.org/10.1016/j.psychsport. 2011.11.009

Turvey, M. T., \& Carello, C. (2011). Obtaining information by dynamic (effortful) touching. Philosophical Transactions of the Royal Society B: Biological Sciences, 366(1581), 3123-3132. https://doi.org/10.1098/rstb.2011.0159

Turvey, M. T. (2018). Lectures on perception: An ecological perspective. New York, NY: Routledge.

Uithol, S., Burnston, D. C., \& Haselager, P. (2014). Why we may not find intentions in the brain. Neuropsychologia, 56, 129-139. https://doi.org/10.1016/j.neuropsychologia.2014.01.010

Van Orden, G. C., Holden, J. G., \& Turvey, M. T. (2003). Self-organization of cognitive performance. Journal of Experimental Psychology. General, 132(3), 331-350. https://doi.org/10.1037/0096-3445. 132.3.331

Wagman, J. B., Shockley, K., Riley, M. A., \& Turvey, M. T. (2001). Attunement, calibration, and exploration in fast haptic perceptual learning. Journal of Motor Behavior, 33(4), 323-327. https://doi.org/ $10.1080 / 00222890109601917$

Warren, W. H. (2006). The dynamics of perception and action. Psychological Review, 113(2), 358-389. https://doi.org/10.1037/0033-295X.113.2.358

Withagen, R., \& Chemero, A. (2012). Affordances and classification: On the significance of a sidebar in James Gibson's last book. Philosophical Psychology, 25(4), 521-537. https://doi.org/10.1080/09515 089.2011 .579424 
Withagen, R., de Poel, H. J., Araújo, D., \& Pepping, G.-J. (2012). Affordances can invite behavior: Reconsidering the relationship between affordances and agency. New Ideas in Psychology, 30(2), 250-258. https://doi.org/10.1016/j.newideapsych.2011.12.003

Publisher's Note Springer Nature remains neutral with regard to jurisdictional claims in published maps and institutional affiliations. 